\title{
Applying Self-directed Learning Strategy to Enhance Nursing Students' Critical Thinking Skills
}

\author{
Heba K. Obied*, Reda A. Abo Gad* \\ *Faculty of Nursing, Tanta University, Tanta, Egypt
}

\begin{abstract}
:
Aim: Today's nurses require to analyze patients' problems, generate creative solutions and make appropriate decisions to improve quality of care, thus our study concerned with enhancing nursing students' CT skills through applying SDL strategy.

Method: quasi experimental (Pretest and posttest) design was used, the study conducted at Nursing Administration Department, Faculty of Nursing, Tanta University. The subject consisted of all (152) $4^{\text {th }}$ year nursing students enrolled in "nursing administration" course, divided into two identical groups (experimental and comparison groups). Four tools were used to collect data; Tool I: California Critical Thinking Disposition Inventory (CCTDI). Tool II: Critical Thinking Stimulus. Tool III: Self-Directed Learning Readiness Scale. Tool IV: Nursing students' SDL and CT knowledge test.

Results: Majority of experimental and comparison nursing student groups had medium and low levels of self assessment regarding SDL readiness skills pre-intervention that improved post intervention. Pre-intervention around three quarts of both experimental and comparison groups fall between levels one and two of holistic CT scoring rubric, which significantly improved post-intervention. Post intervention, there was a statistical significant positive correlation between experimental nursing students' total SDL and total CT and all subscales except inquisitiveness subscale.

Conclusion: SDL method enhanced nursing students' CT skills. Pre-intervention majority of the experimental and comparison nursing students groups had medium and low levels of SDL readiness skills, and also majority of them fall between levels one and two of holistic CT scoring rubric, that significantly improved postintervention. Thus, it is crucial that nurse educators have to stimulate their students to be self learners.
\end{abstract}

Keywords: Self directed learning, critical thinking, learning strategy and nursing students.

\section{Introduction}

Nursing staff is the corner stone of any healthcare organization. To provide high quality patient care those nurses have to be able to think critically to analyze tough situations, generate alternative and innovative solutions, set priorities, solve problem, and make ethical decisions. During the undergraduate education, nursing students should be equipped with those skills to be able to assume their future role and face the challenges associated with their work responsibilities (Kaddoura, 2010; Walsh, 2006). Therefore, nursing schools need to adopt learning models that focus on active students' participation and enhance their self learning skills (Muir Gray, 2001; Jen-Obrom, 2003).

Self directed learning (SDL) is a process where the adult nursing students take the initiative to specify their own learning needs, aims, the appropriate learning sources and strategies, as well as, evaluating their learning results. This process can be established by nursing students independently or with others support including educators, tutors or even classmates. Adding to that, it can be developed at different settings as the academic, continuing education settings or at clinical practice level, by the faculties' educators or nursing manager (Manee, et al., 2006; Şenyuva and Kaya, 2014). SDL has four stages; the first stage is assessing the surrounding environment, one's own readiness for SDL, learning needs and required learning resources. The second stage is planning to promote SDL; the third stage is implementing the learning activity using the most effective learning strategies and finally, evaluating learning outcomes and discovering the future learning needs (Majumdar, 1996; Jenkins et al. 1998).

The success of SDL process depends on the readiness of nursing students to learn, this readiness can be viewed as owning the required personal traits, attitudes, and talents for SDL. Learners with high SDL readiness are aware of their learning responsibility, and act independently. They have the curiosity, and self-confidence in their abilities to organize their times and plan their learning tasks and solve problems effectively (Abd-ElFattah, 2010; Chou and Chen, 2008). Likewise, there are many benefits for applying SDL in nursing including enhancement of students' enthusiasm, self-confidence, autonomy, and refine their clinical skills for continuing education. During SDL process nursing students are also encouraged to build up the ability to appraise the gaps in their knowledge and skills afterwards look for relevant resources to assist them overcoming this gap (Karimi, et al., 2010; Li Ping (Lillian) 2010). 
Self-directed nursing students tend to think about different aspects of new ideas; and rely on independent different resources to gather data rather than being limited to one source. Also, they are able to recall their earlier knowledge and experiences; interpret their points of views and deal with uncertainty. Additionally, they are eager for their learning achievements; apply hypothesis-based approach to learning; takeadvantage-of feedback obtained in other situations; and being autonomous in their learning process. This autonomous strengthens nursing students` learning passion and allows them to continue their lifelong learning on the same basis (Li Ping (Lillian), 2010; Azer, 2008).

Nursing students who experienced SDL are able to discover required knowledge through different methods including internet, journals, textbooks, asking experts, and apply their own experience. So, those students need to be able to judge the validity of searched data and match this data with their learning objectives. Consequently, the process of SDL is involved with students' critical thinking (Manee, et al., 2006). Critical Thinking (CT) has been viewed as a vital curricular outcome in nursing education; moreover it has positive outcomes in both nursing education as well as, nursing practice (Kaddoura, 2010; Walsh, 2006).

CT can be defined as a deliberate compound process encompasses analyzing, interpreting, and evaluating the existing data to make purposeful, self-regulatory judgment that lead to the appropriate decisions (Oderda et al., 2011; Wilgis and McConnell, 2008). However, CT disposition is the personal characteristics that lead to make self-comparison led-decisions when experiencing personal as well as, professional problems. $\mathrm{CT}$ has two dimensions cognitive and affective dispositions. The cognitive disposition encompasses interpretation, analysis, evaluation, inference, explanation and self-regulation skills. These skills are crucial for reasoning process to reach the suitable decision based on the student's set of believes (Simpson and Courtney, 2002).

Whilst, the affective dispositions dimension is also known as intellectual traits; and encompasses inquisitiveness, desire to be knowledgeable, and awareness to employ CT. Furthermore, affective dimension includes trustful of reason, self-confidence in ability to reason, open-mindedness, honesty to face personal biases, carefulness in making judgments, and readiness to adjust personal views (Paul and Elder, 2008; Scheffer and Rubenfeld, 2000). These dispositions are considered as the basics that motivate nursing students to exercise CT of the reasoning process. (Chenworth, 1998; Facione, et al, 1994). Critical thinker nursing students display behaviors of self confidence, flexibility, creativity, curiosity, intellectual honesty, openness and persistence. Furthermore, they exhibit cognitive skills including analyzing, discerning, logical reasoning, and forecasting (Shin, 2006; Scheffer and Rubenfeld, 2000).

Some nursing programs underpin a range of strategies to ensure students' active participation in the learning process and improve their critical thinking capabilities including; utilization of questioning which include thinking skills and the capability to classify and articulate knowledge; small group activities; role-play; simulation; debate; case studies; formal/informal writing assignments and; finally problem based learning (PBL) (Bittner and Tobin, 1998; Oermann, 1997). PBL focuses on learner centered approach that allows nursing students working in small groups to discover solutions for problems. PBL helps students to engage in selflearning and enhance their critical thinking skills (Shahin and Tork, 2013). Even with the recognition given to the significance of CT for nursing practice, different researches regarding PBL based on self-reported satisfaction of nursing students and did not address CT as an outcome of PBL (Williams, 2004; Rideout et al., 2002).

\section{Aim of the study}

Present study aimed to apply SDL strategy to enhance nursing students' CT skills.

Research hypothesis:

Applying SDL strategy expected to enhance nursing students' CT skills.

The Null Hypothesis

Applying SDL strategy will have no significant difference in the nursing students' CT skills.

Materials and Method

Materials

Design: (Pretest and posttest) quasi experimental research design was used.

Setting: The study was conducted at the Nursing Administration Department, Faculty of Nursing, Tanta University.

Subject: All (152) $4^{\text {th }}$ year nursing students enrolled in nursing administration course during the $2^{\text {nd }}$ semester and accepted to participate in the study from the total (175). Those students were divided randomly into two groups experimental group (No.=76) and comparison group (No.=76).

Data collection tools: Four tools were used Tool I: California Critical Thinking Disposition Inventory (CCTDI): developed by Facione et al. (1994) to assess nursing students' CT. The tool consisted of two sections; Section (1) subjects' characteristics included age, gender, residency, previous study and $3^{\text {rd }}$ years' grade. Section (2) consisted of 75 items grouped into seven subscales: truth seeking (12 items), open- 
mindedness (12 items), analyticity (11 items), systematic (11 items), self-confidence (9 items), inquisitiveness (10 items), and maturity (10 items). Nursing students' responses were on a 6-points Likert ranging from "strongly agree" to "strongly disagree". The negative items' scores were reversed, so that a higher score indicated more positive characteristic. For each subscale the score range 10-30 indicated a more intensively negative disposition, from 31 to 39 indicated ambivalence, scores between 40 and 49 indicated increasingly positive dispositions and 50-60 suggested strong positive dispositions towards CT. The total CCTDI scores below 210 denoted a significant opposition, between 210- 280 falls in ambivalent range, above 280-350 positive disposition and above 350 indicated strong positive disposition towards CT. CCTDI overall Cronbach alpha was 0.90 .

Tool II: Critical Thinking Stimulus. This tool was developed by the researchers based on Facione and Facione (2009), Sullivan and Decker (2009), Wise, (2007), and Huber (2006) to assess nursing students' SDL and CT. It consisted of two parts; Part (1) encompassed six problem situations regarding managerial skills included leadership, time management, motivation, delegation, nursing shortage and conflict. Part (2) included different methods used to solve problems as internet, journals, textbooks, asking experts. The nursing students' responses to problem situations were analyzed for evidence of CT skills using Holistic Critical Thinking Scoring Rubric (HCTSR). It encompassed of four levels (table, I); $1^{\text {st }}$ level imply the least of construct and $4^{\text {th }}$ level imply a critical thinker.

Table (I) Holistic Critical Thinking Scoring Rubric

\begin{tabular}{|c|c|}
\hline Consistently does all or almost all of the following: & Level \\
\hline $\begin{array}{l}\text { - } \quad \text { Define problem statement accurately. } \\
\text { - } \quad \text { Infer causes and consequences. } \\
\text { - } \quad \text { Generate alternative solutions. } \\
\text { - } \quad \text { Rnalyze the alternative solutions according to pros and cons. } \\
\text { - } \quad \text { Select the best applicable solution. }\end{array}$ & 4 \\
\hline $\begin{array}{l}\text { - } \quad \text { Define problem statement accurately. } \\
\text { - } \quad \text { Infer causes and consequences. } \\
\text { - } \quad \text { Offers incomplete alternative solutions. } \\
\text { - } \quad \text { Fail to rank the alternative solutions appropriately. } \\
\text { - } \quad \text { Select the best applicable solution. }\end{array}$ & 3 \\
\hline $\begin{array}{ll}\text { - } & \text { Misinterpretation of problem statement. } \\
\text { - } & \text { Specify causes and consequences incompletely. } \\
\text { - } & \text { Offers incomplete alternative solutions. } \\
\text { - } & \text { Draw superficial (pros and cons). } \\
\text { - } & \text { Fail to rank the alternative solutions appropriately. } \\
\text { - } & \text { Wrongly select the best inapplicable solution. }\end{array}$ & 2 \\
\hline $\begin{array}{ll}\text { - } & \text { Fails to specify problem statement. } \\
\text { - } & \text { Specify irrelevant causes and consequences. } \\
\text { - } & \text { Offer irrelevant alternative solutions. } \\
\text { - } & \text { Draw irrelevant (pros and cons). } \\
\text { - } & \text { Fail to rank the alternative solutions appropriately. } \\
\text { - } & \text { Wrongly select inapplicable solution. }\end{array}$ & 1 \\
\hline
\end{tabular}

Tool III: Self-Directed Learning Readiness Scale (SDLRS) developed by Guglielmino (1991), to examine nursing students' level of SDL readiness. The scale consisted of 58 items with a five points Likert Scale, ranging from $1=$ almost never true of me to $5=$ almost always true of me. The readiness was assessed as a total score with possible scores ranging from 58 to 290. A high score indicated high readiness for SDL; students' scores were classified into levels of readiness: low (58-176), below average (177-201), average (202-226), above average (227-251), and high (252-290). The maximum score was 290. The total scale Cronbach's Coefficient alpha reliability was 0.85 .

Tool IV: Nursing students' SDL and CT knowledge test was developed by researchers after reviewing related literatures (Paul \& Elder, 2008; O'Shea, 2003; Simpson and Courtney, 2002; Hiemstra, 1994) to assess nursing students' knowledge about SDL and CT. The tool encompassed 50 questions in form of true \& false, multiple choices, and match. The questions covered SDL "definition, principles, benefits, characteristics, and stages" and CT "definition, strategies, personal indicators, components and, levels". The nursing students' responses for the questionnaire were scored by one for each correct answer and zero for incorrect answer. The total score was 50 grades and represented in varying levels high $\geq 75$, moderate $>60-74$, and low $\leq 60$. 


\section{Method}

- Ethical considerations: Official permission was obtained from Dean of Faculty of Nursing-Tanta University to conduct the study. Researchers met the nursing students to explain the purpose of the study, take their consent, and inform them about their right to withdraw and the confidentially of their data.

- Validity and reliability: Pilot study was done prior data collection to test the tools clarity on $10 \%(\mathrm{~N}=16)$ of nursing students (not included in the sample). Tools reliability was tested by Crombach alpha coefficient. Tools content validity was checked by seven experts in the field of administration, and community nursing, depending on experts' responses and pilot study tools were adjusted and finalized.

\section{- $\quad$ Field work:}

Pre-intervention phase; SDLRS, CCTDI and knowledge test was used to collect both study groups' baseline data (pretest), it consumed about one hour to fill in these tools. Then, the both study groups were provided with six problem situations to analyze one/ week.

Intervention phase; the experimental group attended class workshops via small group discussion using blackboard and data show, the learning package included materials about SDL and CT. The experimental group trained on the steps required to complete the problem situations analysis by being subjected to four different problem situations one/2 week guided by researchers to ensure students' application of SDL. The researchers act as facilitators. They encourage the experimental group towards self-directed learning, and make sure that all students were involved. The collection of data lasted five months. After finishing the study, the comparison group was subjected to the same workshops.

Evaluation phase; the two study groups completed a posttest to measure their improvement in CT and SDLR (the same pretest). Then, the both study groups' were given six problem situations to analyze one/week (same as pre-intervention). The students' responses to problem situations were analyzed by HCTSR, (table, 1).

- Statistical analysis: Data entry and statistical analysis were done using SPSS 19.0 statistical software package. For quantitative data the range, mean, and standard deviation were used. The difference between two means was statistically analyzed using the student paired $(\mathrm{t})$ test. For qualitative data number and percent distribution was calculated. Qualitative categorical variables were compared using chi-square test. Pearson Correlation was used to find the relationship between the CT and SDL. Statistical significance was considered at p-value $<0.05$.

\section{Results}

Table (2) Subjects' personal characteristics

\begin{tabular}{|c|c|c|c|c|c|}
\hline Items & $\begin{array}{c}\text { Experimental } \\
\text { No. }=76\end{array}$ & $\begin{array}{c}\text { Comparison } \\
\text { No. }=76\end{array}$ & Items & $\begin{array}{c}\text { Experimental } \\
\text { No. }=76\end{array}$ & $\begin{array}{c}\text { Comparison } \\
\text { No. }=76\end{array}$ \\
\hline & No. $(\%)$ & No. $(\%)$ & Previous study & No. $(\%)$ & No. (\%) \\
\hline Age & & & Secondary school & $65(86)$ & 68 (89) \\
\hline$\leq 21$ years & $25(33)$ & $24(32)$ & $\mathrm{Ng}$. institute & $11(14)$ & (11) \\
\hline$>21$ years & $51(67)$ & $52(68)$ & $3^{\text {rd }}$ years' grade & & \\
\hline Gender & & & Excellent & $5(6)$ & 3 (4) \\
\hline Male & $27(36)$ & $23(30)$ & V. good & $12(16)$ & $11(15)$ \\
\hline Female & $49(64)$ & $53(70)$ & Good & $41(54)$ & $39(51)$ \\
\hline Live with & & & Acceptable & $18(24)$ & $23(30)$ \\
\hline family & $72(95)$ & $67(88)$ & Residency & & \\
\hline friends & $4(5)$ & $7(9)$ & city & $27(36)$ & $22(29)$ \\
\hline relatives & $0(0)$ & $2(3)$ & village & $49(64)$ & $54(71)$ \\
\hline
\end{tabular}

Table (2) shows subjects' personal characteristics. More than two thirds $(67 \%$ and $68 \%)$ of both experimental and comparison groups fall in the age group $>21$ years, also, $64 \%$ and $70 \%$ of them were female, respectively. More than two thirds $(64 \%$ and $71 \%$ ) of the experimental and comparison led groups lived in villages, and majority (95\% and 88\%) of them lived with their families, respectively. Majority (86\% and $89 \%$ ) of the experimental and comparison led groups graduated from general secondary school, and around half (54\% and $51 \%$ ) of them had good grade in their $3^{\text {rd }}$ year respectively. 
Table (3) Distribution of study groups' total knowledge levels regarding CT and SDL pre and post intervention

\begin{tabular}{|c|c|c|c|c|c|c|c|}
\hline \multirow{2}{*}{\multicolumn{2}{|c|}{$\begin{array}{l}\text { Subject groups' total } \\
\text { knowledge level }\end{array}$}} & \multicolumn{2}{|c|}{ Experimental (No.=76) } & \multirow[b]{2}{*}{$\begin{array}{l}\chi^{2} \\
(\mathbf{P})\end{array}$} & \multicolumn{2}{|c|}{ Comparison (No.=76) } & \multirow{2}{*}{$\begin{array}{l}\chi^{2} \\
(\mathbf{P})\end{array}$} \\
\hline & & $\begin{array}{c}\text { Pre } \\
\text { No. }(\%)\end{array}$ & $\begin{array}{c}\text { Post } \\
\text { No. }(\%)\end{array}$ & & $\begin{array}{c}\text { Pre } \\
\text { No. }(\%)\end{array}$ & $\begin{array}{c}\text { Post } \\
\text { No. }(\%)\end{array}$ & \\
\hline \multirow{3}{*}{$\begin{array}{l}\text { Self directed } \\
\text { learning }\end{array}$} & Low & $56(73.7)$ & $2(2.6)$ & \multirow{3}{*}{$\begin{array}{c}107.6^{* *} \\
(0.000)\end{array}$} & $48(63.2)$ & $50(65.8)$ & \multirow{3}{*}{$\begin{array}{r}1.36 \\
(0.51)\end{array}$} \\
\hline & Medium & $17(22.4)$ & $10(13.2)$ & & $27(35.5)$ & $23(30.3)$ & \\
\hline & High & $3(3.9)$ & $64(84.2)$ & & $1(1.3)$ & $3(3.9)$ & \\
\hline \multirow{3}{*}{$\begin{array}{l}\text { Critical } \\
\text { Thinking }\end{array}$} & Low & $60(78.9)$ & $2(2.6)$ & \multirow{3}{*}{$\begin{array}{c}104.0^{* *} \\
(0.000)\end{array}$} & $44(57.9)$ & $42(55.3)$ & \multirow{3}{*}{$\begin{array}{c}2.05 \\
(0.36)\end{array}$} \\
\hline & Medium & $15(19.7)$ & $23(30.3)$ & & $32(42.1)$ & $32(42.1)$ & \\
\hline & High & $1(1.3)$ & $51(67.1)$ & & $0(0.0)$ & $2(2.6)$ & \\
\hline \multirow{3}{*}{ Total } & Low & $59(77.6)$ & $1(1.3)$ & \multirow{3}{*}{$\begin{array}{l}121.1^{* *} \\
(0.000)\end{array}$} & $52(68.4)$ & $58(76.3)$ & \multirow{3}{*}{$\begin{array}{c}2.52 \\
(0.28)\end{array}$} \\
\hline & Medium & $16(21.1)$ & $9(11.8)$ & & $24(31.6)$ & $17(22.4)$ & \\
\hline & High & $1(1.3)$ & $66(86.8)$ & & $0(0.0)$ & $1(1.3)$ & \\
\hline
\end{tabular}

$* *(\mathbf{p}<0.001)$

Table (3) shows distribution of study groups' total knowledge levels regarding critical thinking and self directed learning pre and post intervention. Pre-intervention high percent $(73.7 \%$ and $63.2 \%)$ and $(78.9 \%$ and $57.9 \%$ ) of both experimental and comparison group had low knowledge level regarding SDL and CT respectively. Post- intervention high percent $(84.2 \%$ and $67.1 \%)$ of the experimental group had high knowledge level regarding SDL and CT respectively. There were statistically highly significant increase in the study subjects' knowledge Level at $(\mathrm{p}<0.001)$ for experimental group only when comparing post and pre levels.

Fig.(1) Study groups' self assessment of their SDL readiness skill pre- intervention.

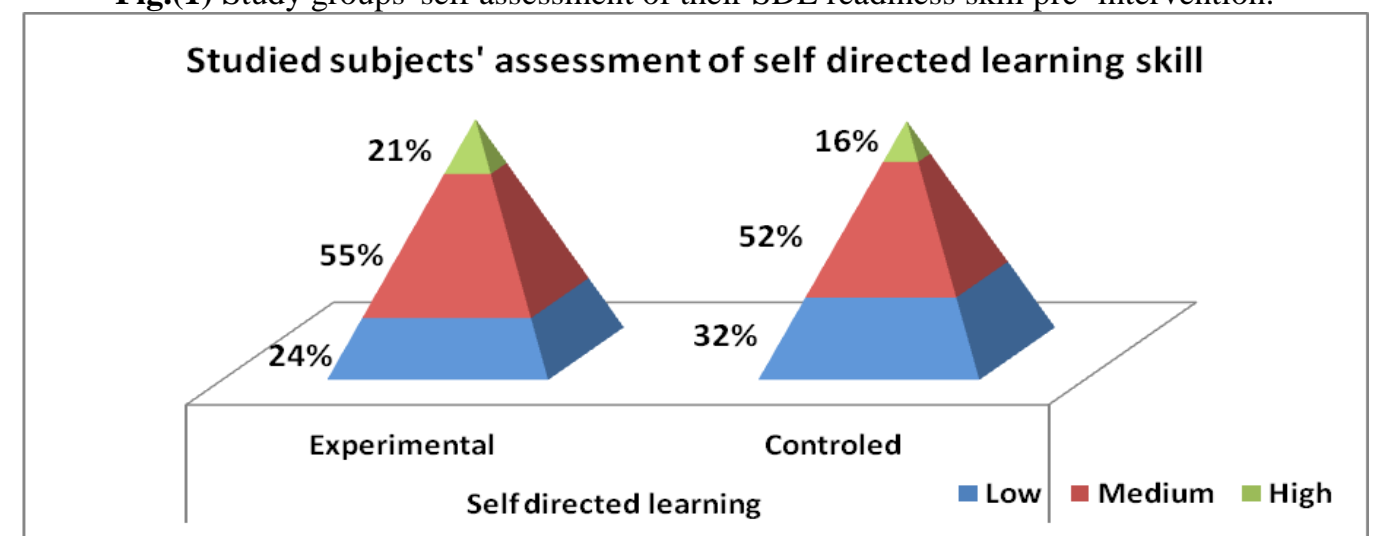

Fig.(1) illustrates study groups' self assessment of their self directed learning readiness skill pre-intervention. Majority (79\% and 84\%) of the experimental and comparison groups had medium and low levels of self assessment regarding SDL readiness skills, respectively.

Table (4). Distribution of the study groups according SDL readiness level pre and post intervention.

\begin{tabular}{|c|c|c|c|c|c|c|}
\hline \multirow{3}{*}{ SDL scale } & \multicolumn{3}{|c|}{ Pre intervention } & \multicolumn{3}{|c|}{ Post intervention } \\
\hline & $\begin{array}{c}\text { Experimental } \\
\text { (No.=76) }\end{array}$ & $\begin{array}{c}\text { Comparison } \\
\text { (No.=76) }\end{array}$ & \multirow{2}{*}{$\begin{array}{l}\mathbf{X}^{2} \\
(\mathbf{P})\end{array}$} & $\begin{array}{c}\text { Experimental } \\
\text { (No.=76) }\end{array}$ & $\begin{array}{c}\text { Comparison } \\
\text { (No.=76) }\end{array}$ & \multirow{2}{*}{$\begin{array}{l}\mathbf{X}^{2} \\
(\mathbf{P})\end{array}$} \\
\hline & No. $(\%)$ & No. $(\%)$ & & No. $(\%)$ & No. $(\%)$ & \\
\hline Low & $15(19.7)$ & $22(28.9)$ & \multirow{5}{*}{$\begin{array}{c}1.48 \\
(0.477)\end{array}$} & $5(6.5)$ & $19(25.0)$ & \multirow{5}{*}{$\begin{array}{c}\text { 65.80 } \\
(0.000 *)\end{array}$} \\
\hline Below average & $39(51.3)$ & $35(46.1)$ & & $6(7.9)$ & $36(47.4)$ & \\
\hline Average & $13(17.2)$ & $10(13.2)$ & & $18(23.7)$ & $11(14.4)$ & \\
\hline Above average & $6(7.9)$ & $7(9.2)$ & & 34 (44.7) & $6(7.9)$ & \\
\hline High & $3(3.9)$ & $2(2.6)$ & & $13(17.2)$ & $4(5.3)$ & \\
\hline
\end{tabular}

Low (58-176), below average (177-201), average (202-226), above average (227-251), and high (252-290).

Table (4) illustrates distribution of the study groups according self directed learning level pre and post intervention. Pre intervention, high percent $(71 \%$ and $75 \%)$ of both experimental and comparison groups had low and below average level regarding self directed learning, respectively. Post intervention high percent $(61.9 \%)$ of the experimental group had above average and high level regarding SDL. Post intervention there was a statistical significant difference between comparison and experimental groups regarding the levels of SDL at $p$ $<0.05$. 
Table (5) Distribution of study groups regarding CT disposition pre intervention

\begin{tabular}{|l|c|c|}
\hline \multirow{2}{*}{ Total CCTDI scale score } & Experimental (No.=76) & Comparison (No.=76) \\
\cline { 2 - 3 } & No. (\%) & No. (\%) \\
\hline Negative disposition ( $\mathbf{2 1 0})$ & $0(0.0)$ & $12(15.79)$ \\
\hline Ambivalent $(\mathbf{2 1 1 - 2 7 9 )}$ & $10(13.16)$ & $62(81.58)$ \\
\hline Positive disposition (280-350) & $64(84.21)$ & $2(2.63)$ \\
\hline Strong positive disposition $(>350)$ & $2(2.63)$ & \\
\hline
\end{tabular}

Table (5) illustrates distribution of study groups regarding CT disposition pre intervention. Majority $(84.21 \%$ and $81.58 \%$ ) of both experimental and comparison groups had positive CT disposition pre program, respectively.

Table (6). Mean and standard deviation of study groups' scores regarding CT subscales pre and post intervention.

\begin{tabular}{|c|c|c|c|c|c|c|c|}
\hline \multirow{3}{*}{$\begin{array}{l}\text { Critical Thinking } \\
\text { subscales }\end{array}$} & \multirow{2}{*}{\multicolumn{2}{|c|}{$\begin{array}{c}\text { Experimental }(\text { No. }=76) \\
\text { Mean } \pm \text { SD }\end{array}$}} & \multirow{3}{*}{$\begin{array}{c}\mathbf{T} \\
(\mathbf{P 1})\end{array}$} & \multirow{2}{*}{\multicolumn{2}{|c|}{$\begin{array}{c}\text { Comparison }(\text { No. }=76) \\
\text { Mean } \pm \text { SD }\end{array}$}} & \multirow{3}{*}{$\begin{array}{c}\mathbf{T} \\
(\mathbf{P 1})\end{array}$} & \multirow{3}{*}{$\begin{array}{c}\mathbf{T} \\
(\mathbf{P} 2)\end{array}$} \\
\hline & & & & & & & \\
\hline & Pre & Post & & Pre & Post & & \\
\hline \multirow{2}{*}{$\begin{array}{l}\text { Truth seeking } \\
\text { Open } \\
\text { mindedness }\end{array}$} & $49.47 \pm 4.28$ & $54.72 \pm 3.46$ & $\begin{array}{c}2.51 \\
(0.002 *)\end{array}$ & $48.76 \pm 4.86$ & $49.86 \pm 4.48$ & $\begin{array}{c}1.24 \\
(0.217)\end{array}$ & $\begin{array}{c}2.87 \\
(0.005 *)\end{array}$ \\
\hline & $48.39 \pm 4.96$ & $55.72 \pm 4.7$ & $\begin{array}{c}4.83 \\
(0.001 *)\end{array}$ & $47.86 \pm 4.56$ & $49.42 \pm 4.78$ & $\begin{array}{c}0.04 \\
(0.967)\end{array}$ & $\begin{array}{c}4.51 \\
(0.001 *)\end{array}$ \\
\hline Analyticity & $45.18 \pm 4.26$ & $50.06 \pm 4.08$ & $\begin{array}{c}3.57 \\
(0.001 *)\end{array}$ & $44.58 \pm 4.84$ & $46.58 \pm 4.78$ & $\begin{array}{c}0.27 \\
(0.786)\end{array}$ & $\begin{array}{c}4.03 \\
(0.001 *)\end{array}$ \\
\hline Systematicity & $43.5 \pm 5.70$ & $49.26 \pm 3.08$ & $\begin{array}{c}3.06 \\
(0.002 *)\end{array}$ & $43.87 \pm 5.25$ & $45.32 \pm 5.32$ & $\begin{array}{c}1.38 \\
(0.172)\end{array}$ & $\begin{array}{c}3.92 \\
(0.001 *)\end{array}$ \\
\hline Self confidence & $37.05 \pm 9.00$ & $41.32 \pm 4.98$ & $\begin{array}{c}3.71 \\
(0.001 *)\end{array}$ & $35.32 \pm 8.11$ & $35.68 \pm 7.7$ & $\begin{array}{c}0.26 \\
(0.798)\end{array}$ & $\begin{array}{c}4.05 \\
(0.001 *)\end{array}$ \\
\hline Inquisitiveness & $40.03 \pm 4.66$ & $45.24 \pm 3.54$ & $\begin{array}{c}2.25 \\
(0.027 *)\end{array}$ & $39.37 \pm 4.79$ & $40.08 \pm 4.92$ & $\begin{array}{c}0.435 \\
(0.647) \\
\end{array}$ & $\begin{array}{c}3.14 \\
(0.002 *)\end{array}$ \\
\hline $\begin{array}{l}\text { Cognitive } \\
\text { Maturity }\end{array}$ & $40.18 \pm 4.02$ & $45.22 \pm 3.9$ & $\begin{array}{c}3.33 \\
(0.001 *)\end{array}$ & $39.55 \pm 4.67$ & $40.32 \pm 4.86$ & $\begin{array}{c}1.63 \\
(0.107)\end{array}$ & $\begin{array}{c}3.39 \\
(0.001 *)\end{array}$ \\
\hline Total & $303 \pm 16.06$ & $341.5 \pm 15.82$ & $\begin{array}{c}5.48 \\
(0.001 *)\end{array}$ & $299.31 \pm 18.53$ & $306.1 \pm 17.4$ & $\begin{array}{c}1.16 \\
(0.249)\end{array}$ & $\begin{array}{c}5.83 \\
(0.001 *)\end{array}$ \\
\hline
\end{tabular}

$P 1$ comparison between pre and post in the same group

$P 2$ comparison between post in each group.

$\mathbf{P}<0.05$

Table (6) shows mean and standard deviation of study groups' scores regarding critical thinking subscales pre and post intervention. Four of the seven subscale mean scores (truth-seeking, open-minded, analyticity, and systematisty) for both the experimental and comparison nursing students groups were found to be $>40$, while, self confidence, inquisitiveness and cognitive maturity subscales were $\leq 40$ pre intervention. The highest mean score for both the experimental and comparison groups pre-program were found to be $49.47 \pm 4.28$ and $48.76 \pm 4.86$, respectively regarding truth-seeking. While, the lowest mean score for both the experimental and comparison groups pre-program were found to be $37.05 \pm 9.00$ and $35.32 \pm 8.11$, respectively regarding self confidence. Pre-program total mean scores $(303 \pm 16.06$ and $299.31 \pm 18.53)$ for experimental and comparison groups, respectively showed a positive disposition towards critical thinking. Table also shows significant improvement between the experimental groups' mean-scores pre and post intervention at all CT subscales at $\mathrm{p}<$ 0.05 .

Table (7). Correlations coefficient between nursing students' total self directed and critical thinking subscales

\begin{tabular}{|c|c|c|c|c|}
\hline \multirow{3}{*}{ CT Subscales } & \multicolumn{4}{|c|}{ Nursing students' total self directed } \\
\hline & \multicolumn{2}{|c|}{ Experimental (No.=76) } & \multicolumn{2}{|c|}{ Comparison (No.=76) } \\
\hline & $\mathbf{r}$ & P-value & $\mathbf{r}$ & P-value \\
\hline Truth seeking & 0.397 & $0.001 *$ & 0.047 & 0.312 \\
\hline Open mindedness & 0.277 & $0.001 *$ & 0.306 & 0.084 \\
\hline Analyticity & 0.359 & $0.001 *$ & 0.060 & 0.195 \\
\hline Systematicity & 0.420 & $0.020 *$ & 0.226 & 0.247 \\
\hline Self confidence & 0.595 & $0.001 *$ & 0.330 & $0.001^{*}$ \\
\hline Inquisitiveness & 0.037 & 0.202 & -0.051 & 0.271 \\
\hline Cognitive Maturity & 0.443 & $0.001 *$ & 0.503 & $0.003^{*}$ \\
\hline Total & 0.540 & $0.001 *$ & 0.030 & 0.091 \\
\hline
\end{tabular}


Table (7) shows correlations coefficient between nursing students' total self directed and critical thinking subscales post intervention. As shown in the table there is a statistical significant positive correlation (at $\mathrm{P}<0.05$ ) between experimental nursing students' total SDL and total CT and all subscales except inquisitiveness subscale $(\mathrm{r}=0.037, \mathrm{p}=0.202)$. While, there was no statistical significant correlation between comparison nursing students' total SDL and their CT except self confidence and cognitive maturity subscales $(\mathrm{r}=0.330, \mathrm{p}=0.001 * \& \mathrm{r}=0.503, \mathrm{p}=0.003 *)$. As the significant $(\mathrm{p})$ value was less than 0.05 , the null hypothesis is rejected.

Table (8). Distribution of the study groups according to Holistic Critical Thinking Rubric scores pre and post intervention

\begin{tabular}{|l|c|c|c|c|}
\hline \multirow{2}{*}{$\begin{array}{c}\text { Holistic Critical Thinking Scoring } \\
\text { Rubric Levels }\end{array}$} & \multicolumn{2}{|c|}{ Experimental (No.=76) } & \multicolumn{2}{c|}{ Comparison (No.=76) } \\
\cline { 2 - 5 } & Pre & Post & Pre & Post \\
\cline { 2 - 5 } & No. $(\boldsymbol{\%})$ & No. (\%) & No. (\%) & No. (\%) \\
\hline Level four & $13(17.2)$ & $49(64.5)$ & $11(14.5)$ & $12(15.8)$ \\
\hline Level three & $9(11.8)$ & $23(30.3)$ & $9(11.8)$ & $10(13.2)$ \\
\hline Level two & $46(60.5)$ & $3(3.9)$ & $49(64.5)$ & $45(59.2)$ \\
\hline Level one & $8(10.5)$ & $1(1.3)$ & $7(9.2)$ & $9(11.8)$ \\
\hline
\end{tabular}

Table (8) shows distribution of the study groups according to holistic critical thinking rubric scores pre and post intervention. Pre-intervention around three quarts $(71 \%$ and $73.7 \%)$ of both experimental and comparison groups, respectively fall between levels one and two of holistic critical thinking scoring rubric. While, post-intervention majority $(94.8 \%)$ of the experimental group fall in levels three and four, of holistic CT scoring rubric, while comparison group did not view any remarkable change

Table (9). Distribution of experimental group according to the different methods used to solve problem situations $(n=76)$

\begin{tabular}{|c|c|c|c|}
\hline Resources guide & $(\mathbf{\%}) \mathbf{N}$ & Academic resources & $(\mathbf{\%}) \mathbf{N}$ \\
\hline People & $13(17.1)$ & Textbook & $46(60.5)$ \\
\hline Library & $63(82.9)$ & Journals & $9(11.9)$ \\
\hline Media & $0(0.00)$ & Internet & $21(27.6)$ \\
\hline
\end{tabular}

Table (9) shows distribution of experimental group according to the methods used to solve problem situations. Majority of the experimental group (82.9\%) depend on library to solve problem situations. High percent $(60.5 \%)$ of the experimental group used textbooks, and around one quarter $(27.6 \%)$ utilized internet to solve problem situations.

\section{Discussion}

Healthcare field is rapidly changing as a result of continuously advancing technology; subsequently today's nursing students must be self-learners and can manage their learning process independently. Self directed nurses tend to be self-confident, creative, inquisitiveness, honest, open-minded and persistence. These traits are required to be critical thinker thus our study concerned with enhancing nursing students' CT skills through applying SDL strategy (Yıldırım, 2010).

\section{Nursing students' pre intervention self assessment of SDL and CT:}

Current study results revealed that majority of the experimental and comparison nursing student groups had medium and low levels of self assessment regarding SDL readiness skills. This might be explained as those nursing students rely heavily on their educators to guide their learning process, they may be lacking self confidence and do not trust their abilities, thus they need to be challenged to take an active role to participate in planning and designing their learning process. These findings were going with Senyuva and Kaya (2014), they found that their study subjects had low level of self-learning readiness. While, Prabjandee and Inthachot (2013) and Klunklin et al. (2010) found that their study subjects had high and moderate level of SDL readiness.

Majority of both experimental and comparison groups had positive CT disposition pre program. This can be reasonable as those fourth year nursing students had previous clinical experience in the previous three years that enabled them to analyze patients complains, prioritize their problems, and apply the appropriate interventions. These results go in the same line with Wangensteen et al (2010), Shin et al (2006), Megahed (2004) and Hicks et al (2003) they found that nursing students had a positive disposition toward CCTDI. Also, Shin (1996) concluded that baccalaureate nursing students' CT score was significantly higher than that of diploma students. This differed from findings of Tiwari et al (2003) they found that nursing students' had ambivalent level regarding critical thinking disposition. 
Present study results revealed that for the experimental and comparison groups pre intervention, four of the seven CT subscales mean scores found to be $>40$ including (truth-seeking, open-minded, analyticity, and systematisty) while, self confidence, inquisitiveness and cognitive maturity subscales were $\leq 40$. These findings can be interpreted as those nursing students have practiced problem solving and case study methods during their clinical work assignments thus, their open-minded, analyticity and systematisty were high.

Furthermore, present study data was reassuring where nursing students with positive disposition towards systematicity are able to organize and prioritize patient care, make effective decisions, and are attentive. In fact, our nursing curricula is based on problem-based learning that enabled students to specify problems accurately, analyze situation to conclude causes and consequences, generate solutions, carryout solutions, and evaluate the outcomes. These findings were incongruent with Hicks et al (2003) they found that nursing students showed limited CT dispositions regarding analyticity, open-mindedness, and truth-seeking.

In contrary, present results were not promising where low cognitive maturity scores in CT scale indicates that our nursing students could not realize that some complex problems can have more than one solution. While, low inquisitiveness score revealed they were lacking the curiosity for learning that influence their ability to expand proficient knowledge and practical skills as mentioned by Shin (2006). This can be viewed as a consequence of using teaching methods that require only a single best answer to a given problem. Differently from our findings Wangensteen (2010), Profetto-McGrath (2003), and May et al. (1999) reported the highest subscale mean score in CT scale was regarding inquisitiveness. Profetto-McGrath (2003) stated that high inquisitiveness reveal eagerness to gain knowledge even it have not immediate use.

Present study results showed the highest mean score for both the experimental and comparison groups pre-program were regarding truth-seeking, while, the lowest mean score were regarding self confidence. These results are comforting since Facione (1995) mentioned that high score of truth-seeking infer that nursing students in a given situation are being excited to search for the most relevant facts, ask questions, and be frank and objective about tracking inquiry despite the consequences do not match their interests or opinions. Whilst, low score in self-confidence subscale shows distrust those nursing students lay in their reasoning process that can be due to their limited experience and immaturity. These results were opposite to those of Wangensteen et al (2010), Tiwari et al. (2003), Profetto-McGrath et al. (2003), and May et al. (1999) they revealed that the lowest mean score was regarding truth-seeking subscale.

\section{Nursing students' knowledge about self- directed learning and critical thinking:}

Pre-intervention high percent of both experimental and comparison groups had low knowledge level regarding SDL and CT, but post- intervention there were statistically high significant increase in the experimental group' knowledge Level at $(\mathrm{p}<0.001)$. The present study subjects were lacking knowledge regarding SDL and CT, so they were interested to gain knowledge regarding these skills. According to Liu et al. (2010) building good knowledge base and desire to share knowledge among participants enhanced their knowledge caliber.

\section{Nursing students' post intervention self assessment of SDL and CT stimulus:}

Present results indicated that there was positive statistical significant correlation $($ at $\mathrm{P}<0.05)$ between experimental nursing students' total SDL and total CT all subscales except inquisitiveness. While, there was no statistical significant correlation between comparison nursing students' group total SDL and their CT except self confidence and cognitive maturity subscales. SDL enable nursing students to control and shape their learning experience, through application of reflective judgment that is required to be critical thinker. These results supported by Choi et al. (2014) they found positive significant correlation between CT and SDL. Contradicting to these results Hashemabadi et al. (2013) found no significant relationship between SDL and CT.

The study results revealed that post intervention high percent of the experimental group had above average and high levels regarding SDL. Also, there was a statistical significant difference between comparison and experimental groups regarding the levels of SDL at $\mathrm{p}<0.05$, post intervention. This improvement in the experimental nursing students' readiness to SDL was apparently due to the intervention. These results were confirmed by Senyuva and Kaya (2014) they found that their study subjects' level regarding self-learning readiness increased above threshold after their intervention.

Current study findings showed that pre-intervention around three quarts of both experimental and comparison groups fall between levels one and two of holistic CT scoring rubric. While, post-intervention and analyzing problem scenarios, majority of the experimental group fall in levels three and four of holistic CT scoring rubric, and still comparison group did not view any remarkable change. Through problem situations nursing students' can gain many skills such as analyzing relationships among elements of a given situation, justifying their reasoning through facts, and being able to confront their own and others assumptions. These results were confirmed by Lee (2004); Facione and Facione's (1996) as they found that students' receive experimental intervention had significant improvement in their CT scoring rubric posttest than pretest. Also, 
Halpern (1999) reported that permitting students to apply the knowledge and skills into other domains enhance their CT skills.

Lowenstein \& Bradshaw (2001) stated that imposing students to complex situations, and encourage them to apply discussion and debates regarding problem situations enhance their performance. (Bastable, 2003) and Camiah (1998) proposed that using problems based learning in adult learning provide them with opportunity to build on prior experience, integrate knowledge, and apply these knowledge in future situations. Also, they noted that problem based learning promotes teamwork thus, it encourages developing CT skills. So, using more open and flexible learning methods is crucial in nursing education.

Also, present study result revealed that there was a statistical significant improvement in the experimental groups' mean-scores post intervention at all CT subscales at $p<0.05$. These findings proof the notion that CT skill can be enhanced through applying SDL and PBL. According to Rowles and Brigham (2005), students' CT skills can be fostered through educational programs based on problems situations. Guglielmino et al (2004) and Kerka (2005) found that SDL help student to accept responsibility for their learning and being able to select their own goals and take active steps to achieve these goals, thus SDL can improve students' academic achievement. In keeping with this Bartlett and Cox (2002) reported an improvement in CCTDI scores of 28 physical therapy students after a year-long program. Yıldırım (2010) found that nursing studentsactive participation in activities such as PBL, case studies and group discussions enhanced students' total CT disposition score.

Present study revealed that majority of the experimental group depended on library to solve problem scenarios. High percent of the experimental group used textbooks, and more than one quarter used internet to solve problem scenarios. According to Quarstein \& Peterson (2001) using library and textbooks are helpful methods for adult learners to gain knowledge about different topics thus; they base their solving of problems on accurate facts and explore important issues, bearing in mind different viewpoints. Also Youngblood and Beitz (2001) confirmed these results and found that portfolio development, clinical journals, clinical reaction papers, group presentation were perfect strategies to enhance CT.

\section{Conclusion}

It has been proven that SDL enhanced nursing students' CT skills. Pre-intervention majority of the experimental and comparison nursing students groups had medium and low levels of self assessment regarding SDL readiness skills. Nursing students' had an ambivalent level regarding self confidence, inquisitiveness and cognitive maturity subscales pre-intervention. Pre-intervention around three quarts of both experimental and comparison groups fall between levels one and two of holistic critical thinking scoring rubric. While, postintervention majority of the experimental group fall in levels three and four, of holistic critical thinking scoring rubric, that shows significant improvement of experimental nursing students' critical thinking skill. Based on this we recommend:

- Nursing faculties need to redesign undergraduate curricula to enhance students' self-confidence and cognitive maturity to generate multiple innovative solutions.

- Nurse educators demand to stimulate student's CT through introduce interesting and challenging problem scenarios. Also they need to encourage students to ask questions, challenge them to search for the most relevant facts, and be objective about tracking inquiry to raise their confidence in their reasoning process.

- $\quad$ Further research: need to explore effect of using CCTDI to assess nurse educators' teaching techniques for instructional effectiveness.

[1]. Abd-El-Fattah M. (2010). Garrison's model of self-directed learning: preliminary validation and relationship to academic achievement. The Spanish Journal of Psychology, 13(2):586-96.

[2]. Azer, S.A. (2008). Navigating problem-based learning. London: Elsevier

[3]. Bartlett D.J. \& Cox P.D. (2002). Measuring change in students' critical thinking ability: implications for health care education. Journal of Allied Health 31: 64-9.

[4]. Bastable, S.B. (2003). Nurse as educator: Principles of teaching and learning for nursing practice. Boston: Jones and Bartlett.

[5]. Bittner NP, Tobin D., (1998). Critical thinking: strategies of clinical practice. Journal for Nurses in Staff Development; 14(6): 26772.

[6]. Camiah, S. (1998). Current educational reforms in nursing in the United Kingdom and their impact on the role of nursing lectures in practice: A case study approach. Nurse Education Today, 18:368-79.

[7]. Chenworth L. (1998) Facilitating the process of critical thinking for nursing. Nurse Education Today; 18(4): 281-92.

[8]. Choi, E., Lindquist, R., \& Song, Y. (2014). Effects of problem-based learning vs. Traditional lecture on Korean nursing students' critical thinking, problem-solving, and self-directed learning. Nurse education today, 34(1): 52-6.

[9]. Chou, P. \& Chen, W. (2008). Exploratory study of the relationship between self-directed learning and academic performance in a web-based learning environment. Online Journal of Distance Learning Adminstration, 11(1), 22-27.

[10]. Facione NC, Facione PA, Sanchez CA. (1994). Critical thinking disposition as a measure of competent clinical judgement: The development of the California Thinking Disposition Inventory. Journal of Nursing Education; 33: 345-350.

[11]. Facione, PA, Sánchez CA, Facione, NC \& Gainen, J., (1995). The disposition toward critical thinking. Journal of General Education. 1995; 44(1): 1-25. 
[12]. Facione, P. and Facione, N., (2009). Measured Reasons LLC, Hermosa Beach. California Academic Press / Insight Assessment, Millbrae.

[13]. Guglielmino M. (1991). Developing self-directed learners: Why and how. Changing Schools, 19 (2), 6-7 \&11.

[14]. Guglielmino M., Long B. \& Roger H. (2004). Historical perspectives series: Self-direction in learning in the United States. International Journal of Self-Directed Learning, 1 (1), 1-25.

[15]. Halpern F. (1999). Teaching for Critical thinking: helping college students develop the skills and dispositions of a critical thinker. New Directions for Teaching and Learning, 80, 69-74.

[16]. Hashemabadi G., Garavand H., Mohammadzadeh A. Hosseini S. (2013). A survey on relation between tendency to critical thinking and self directed in nursing and midwifery students and its role on their academic achievement. Journal of Medical Education and Development, 7(4):15-27.

[17]. Hicks F., Merritt S., and Elstein A. (2003). Critical Thinking and Clinical Decision Making In Critical Care Nursing: A Pilot Study. HEART \& LUNG. 32(3):169-

[18]. Hiemstra R. (1994). Self-directed learning. In T. Husen \& T. N.Postlethwaite (Eds.), The International Encyclopedia of Education (second edition), Oxford: Pergamon Press. Reprinted here by permission

[19]. Huber D. Leadership and Nursing care management, $2^{\text {nd }}$, Saunders, Philadelphia,2006: 242.

[20]. Jen-Obrom S. (2003) Self-Directed Learning: Innovation for Teaching and Learning, Chulalongkorn University, Thailand.

[21]. Jenkins T., Carlson J.\& Herrick C. (1998) Developing selfdirected learning modules. Journal of Nursing Staff Development 14, $17-22$.

[22]. Kaddoura M.(2010). New graduate nurses' perceptions of the effects of clinical simulation on their critical thinking, learning, and confidence. Journal of Continuing Education in Nursing, 41(11), 506-516.

[23]. Karimi R., Arendt S., Cawley P., Buhler V., Elbarbry F., Roberts C.(2010). Learning bridge: curricular integration of didactic and experiential education. American Journal of Pharmaceutical Education. 74 (3): $48 . \quad$ PMid:20498741 http://dx.doi.org/10.5688/aj740348.

[24]. Kerka S. (2005). Applying adult learning theory: Self-directed learning and transformational learning in the classroom. California Adult Education Research Digest, 3, 14. Retrieved May 11, 2008, from http://www.academia.edu/3308156/self-directedlearning.

[25]. Klunklin A., Viseskul N., Sripusanapan A.,\& Turale S.(2010). Readiness For self-directed learning among nursing students in Thailand. Nursing and Health Sciences, 12(2): 177-81.

[26]. Lee K.( 2004). Effects of Individual versus online collaborative case study learning strategies on critical thinking of undergraduate students. Doctor of Philosophy. Texas University-Austin.

[27]. Li Ping (Lillian) (2010). Teachers' facilitation in self-directed learning for Chinese college students in English as a foreign language courses. Published Master thesis. The Graduate Faculty University of Wisconsin-Platteville.

[28]. Liu KL, Chang CC, Hu L. (2010). Exploring the effects of task characteristics on knowledge sharing in libraries. Library Review. 455-468.

[29]. Lowenstein, A.J., \& Bradshaw, M.J. (2001). Fuszard's innovative teaching strategies in nursing. $3^{\text {rd }}$ ed. Gaithersburg, MD: Aspen.

[30]. Majumdar B. (1996) Self-directed learning in the context of a nursing curriculum: development of a learning plan. Curationis: South African Journal of Nursing 19, 43-46.

[31]. Manee A., Rujires T., Prapis C. (2006). Self-Directed Learning Readiness, Critical Thinking Skill, and Self Esteem in Nursing Students Studying Through Problem Based Learning. Thai J Nurs Res, 10 (1) : 59-72.

[32]. MayB.A., Edell V., Butell S., Doughty J.\&Langford C. (1999). Critical thinking and clinical competence: a study of their relationship inBSN seniors. Journal of Nursing Education 38(3), 100-110.

[33]. Megahed M. (2004) Critical Thinking among University Nursing Students and Interns. Unpublished Master Thesis. Faculty of Nursing Tanta University Egypt.

[34]. Muir Gray, J.A. (2001). Developing the evidence management skills of individuals, Evidence-based health care, $2^{\text {nd }}$ ed. Churchill Livingstone, London.

[35]. Oderda, G. M., Zavod, R. M., Carter, J. T., Early, J. L., Joyner, P. U., Kirschenbaum, H., Plaza, C. M. (2011). An environmental scan on the status of critical thinking and problem solving skills in colleges/ schools of pharmacy: Report of the 2009-2010 academic affairs standing committee. American Journal of Pharmaceutical Education, 74(10): S6.

[36]. Oermann MH., (1997). Evaluating critical thinking in clinical practice. Nurse Education 22(5): 25-28.

[37]. O'Shea E., (2003). Issues and innovations in nursing education. Self-directed learning in nurse education: a review of the literature. Journal of Advanced Nursing 43(1), 62-70.

[38]. Paul, R., \& Elder, L. (2008). The Miniature Guide to Critial Thinking Concepts and Tools (5 ${ }^{\text {th }}$ ed.): The Foundation for Critical Thinking.

[39]. Prabjandee D. and Inthachot M. (2013). Self-Directed Learning Readiness of College Students in Thailand. Journal of Educational Research and Innovation Spring ; 2(1):

[40]. Profetto-McGrath J. (2003) The relationship of critical thinking skills and critical thinking dispositions of baccalaureate nursing students. Journal of Advanced Nursing 43(6), 569-577.

[41]. Quarstein, V. A., \& Peterson, P. A. (2001). Assessment of cooperative learning: A goalcriterion approach. Innovative Higher Education, 26(1), 59-77.

[42]. Rideout, E., England-Oxford, V., Brown, B., Fothergill-Bourbonnais, F., Ingram, C., Benson, G., Ross, M., Coates, A. (2002) A comparison of problem-based and conventional curricula in nursing education. Advances in Health Sciences Education 7, 3-17.

[43]. Rowles, C. J., \& Brigham, C. G. (2005). Strategies to promote critical thinking and active leaming. In D. M. Billings \& J. A. Halstead (Eds.), Teaching in nursing: A guide for faculty. St. Louis. MO: Elsevier.

[44]. Scheffer, B. K., \& Rubenfeld, M. G. (2000). A consensus statement on critical thinking in nursing. Journal of Nursing Education, 39(8), 352-359.

[45]. Şenyuva E. and Kaya H. (2014) Effect self directed learning readiness of nursing students of the web based learning Procedia Social and Behavioral Sciences. 152,386 - 392387

[46]. Shahin, E. and Tork H. (2013) Critical thinking and self-directed learning as an outcome of problem-based learning among nursing students in Egypt and Kingdom of Saudi Arabia. Journal of Nursing Education and Practice, 3(12):103-

[47]. Shin K., Lee J., \& Kim K. (2006) Critical thinking dispositions in baccalaureate nursing students Journal of Advanced Nursing 56(2), 182-189

[48]. Shin K.R. (1996) A study of critical thinking ability of associate and baccalaureate degree nursing students. Journal of Korean Academy of Nursing 26: 43-52. 
[49]. Simpson E.,\& Courtney M. (2002) Critical thinking in nursing education: A literature review. School of Nursing, Queensland University of Technology. Queensland, Australia

[50]. Sullivian EL, and Decker PJ.(2006) Effective leadership and management in nursing, $6^{\text {th }}$ ed. Pearson Education, INC., Upper Sadelle River, NewJersy.07458: 320

[51]. Tiwari A. , Avery A. \& Lai P. (2003) Critical thinking disposition of Hong Kong Chinese and Australian nursing students .Journal of Advanced Nursing 44(3): 298-307

[52]. Walsh, C.\& Seldomridge, L.(2006). Critical thinking: Back to square two. Journal of Nursing Education, 45(6), $212-219$.

[53]. Wangensteen S. (2010), Johansson I .S. , Bjorkstrom M.E. \& NORDSTROM G. BJO“ RKSTRO“ M., and Nordstro“m G. Critical thinking dispositions among newly graduated nurses. Journal of Advanced Nursing 66(10), 2170-2181. doi: 10.1111/j.13652648.2010.05282.x

[54]. Wilgis,M., \&McConnell, J. (2008). Concept mapping: An educational strategy to improve graduate nurses' critical thinking skills during a hospital orientation program. Journal of Continuing Education in Nursing, 39(3), 119-126.

[55]. Williams, B., (2004). Self-direction in a problem based learning program. Nurse Education Today 24, $277-285$.

[56]. Wise. P.S. (2007)Leading and Managing in nursing, $4^{\text {th }}$ ed., Texas Teaching University, Health Science Center, Texas, Mosby Comp.: 516-521.

[57]. Yıldırım, Ö.B. (2010). Hemşirelikte eleştirel düşünme uygulamalı yaklaşım. Özsoy SA. Eds. Tuna Matbaacılık, Aydın, 41-53.

[58]. Youngblood, N., \& Beitz, J. M. (2001). Developing critical thinking with active-learning strategies. Nurse Educator, 26(1), 39-42. 